\title{
The first special issue of the Journal of Hematopathology
}

\author{
Han van Krieken
}

Published online: 26 May 2011

(C) Springer-Verlag 2011

The issue you have in hand or on your screen is the first special issue of the Journal of Hematopathology. At the editorial board meeting of the journal during the EAHP meeting in Uppsala, it was put forward that special issues might serve our readers well, and thanks to the inspiring work of Jon VanderWalt and the persons who wrote reviews upon his request, we now have this issue available. Bone marrow histopathology is a difficult and rapidly changing field for hematopathologists. It is in the myeloid neoplasms where most changes have occurred in the update of the WHO classification on hematological malignancies and these changes include quite a few disorders in which the bone marrow biopsy is relevant. We are lucky that there is an active group of specialists that convene regularly, partly in association with the EAHP partly independently. One such meeting was organized by Jon VanderWalt in London recently. This meeting was a great success with many attendants and many interesting lectures. It is with great pleasure that I can present to you several of the lectures now in review form.

One may ask what the additional value of reviews is after such a meeting. Of course they are valuable for persons who were not there, but probably also for the attendants as a memory. You may be aware of the book Moonwalking with Einstein by Joshua Foer, which deals with memory and how to improve it. I was struck by the chapter in which he describes how he improved very well in memorizing irrelevant items in a few months but then reached a plateau. He analyzed what was happening and described a body of literature in which it is found that real experts not only practice at lot but actually seek challenges and learn from mistakes. He gave the example that aged surgeons are often better than younger ones, but that this is not the case for mammographists: the reason is that a surgeon gets immediate feedback from mistakes. How does that translate to pathology, especially hematopathology? Of course a good hematopathologist knows his/her literature, hence the reviews in this issue. He or she practices by doing cases daily (Is there a minimum number to see to remain good?), but do we learn enough from our mistakes? Do we get enough immediate feedback? In fact, I do remember several of my mistakes very vividly and think I have learned from them. Most often they came forward by very good clinicians who are very critical on pathology, and although it is of course not nice when this happens, it is in fact a key issue to improve. Therefore I propose to you as a topic of a special issue or maybe a new series in the Journal of Hematopathology the mistakes I have learned from. I invite you all to send me an article, case report, or letter on your own mistake you learned the most of. Please send me your idea in brief so that I can select a nice coherent series of cases (j.vankrieken@pathol.umcn.nl). I hope you find this challenge as interesting as I do. Enjoy the special issue.

Han van Krieken

H. van Krieken $(\triangle)$

Department of Pathology,

Radboud University Nijimegen Medical Center,

Postbus 9101,

6500 HB Nijimegen, The Netherlands

e-mail: j.vankrieken@pathol.umcn.nl 